\title{
Microvascular obstruction after successful fibrinolytic therapy in acute myocardial infarction. Comparison of reteplase vs reteplase+abciximab: A cardiovascular magnetic resonance study
}

\author{
ANTONELLO ZONI', PETER KNOLL'², TIZIANO GHERLI' \\ ${ }^{1}$ Heart Department, University Hospital of Parma, Parma - Italy \\ ${ }^{2}$ Division of Cardiology, General Hospital of Bolzano - Italy
}

\begin{abstract}
Background. About one third of patients with TIMI 3 after reperfusion have evidence of microvascular obstruction (MO) which represents an independent predictor of myocardial wall rupture. This explains all efforts made to prevent MO. Magnetic resonance imaging (MRI) has proved to be particularly useful in detecting MO. The aim of this study was to evaluate with MRI if different fibrinolytic regimens in acute myocardial infarction display different effects on left ventricle $(L V)$ volumes and ejection fraction (EF), as well as on myocardial infarct size (MIsz) and MO.
\end{abstract}

Methods. Twenty male patients, mean age 58 years, affected by acute myocardial infarction, ten anterior and ten inferior, were treated with: full dose reteplase in ten, and half dose reteplase plus full dose abciximab $(R+A b c x)$ in the other ten patients. In the fourth day after hospital admission, MRI STIR T2 images were used to quantify MIsz, while 2dflash cineloops were used after the injection of gadolinium, to quantify $L V$ volumes, $E F$ and to detect $M O$.

Results. $L V$ EF was higher in $R+A b c x 51 \pm 10$ than in reteplase $41 \pm 8$. MIsz was similar in both treatment groups: however a close relationship was present between MIsz and EF in the reteplase group indicating that the greater the MIsz the lower the EF. In $R+A b c x$ this relationship was no longer present, suggesting a protective effect of the drug on microcirculation. In fact extensive $M O$ was present in $25 \%$ of all cases, $80 \%$ of which in the reteplase group while only $20 \%$ in $R+A b c x$.

Conclusion. $R+A b c x$ prevents MO: compared to traditional fibrinolytic therapy it allows better LV function and most likely improved long term survival. (Heart International 2006; 2: 54-65)

KEY WORDS: Magnetic resonance, Myocardial infarction, Microvascular obstruction

\section{INTRODUCTION}

The structure and the role of microvasculature has been progressively clarified in this last decade $(1,2)$. We now have adequate information on the time course and percentage occurrence of microvascular obstruction (MO). We know that the venules are the site of leukocyte adhesion during inflammation and that their endothelial surfaces express a number of adhesion molecules, whose production is significantly up-regulated after the onset of tissue injury (3). Similarly we know that about one fifth to one third of patients with TIMI grade 3 flow after mechanical or pharmacological reperfusion show evidence of $\mathrm{MO}(4,5)$ which, in turn, seems the basis of 
intracardiac hemorrhage $(6,7)$ and of the development of myocardial wall rupture (8).

In patients with acute coronary syndromes undergoing $\mathrm{PCl}$, aspiration of the coronary artery has revealed thrombus with or without plaque components in 15$50 \%$ of the patients $(9-11)$.

This means that in a large percentage of cases, $50-$ $85 \%, \mathrm{MO}$ is a dynamic phenomenon which begins gradually and progressively develops after the occluded vessel has been reopened $(12,13)$. It then persists for at least 1 month after reopening of the epicardial coronary artery, predicting worse scar thinning, infarct expansion, poor survival, and ultimately annulling the effect of $\mathrm{PCl}(14-16)$.

This explains all efforts made to prevent $\mathrm{MO}$ with mechanical devices $(17,18)$ or with pharmacological strategies (19-33).

The rational of focusing downstream the open artery hypothesis may be further emphasized by considering that all cardiac ruptures, likely the main cause of death in the in-hospital course of myocardial infarction, seem to lag behind $\mathrm{MO}$ which represents a significant, and in all probability the principal independent predictor of cardiac rupture $(34,35)$.

Magnetic Resonance Imaging (MRI) has proved to be of great value in detecting and monitoring $\mathrm{MO}$ after occlusion and reopening of the coronary artery, both in experimental and in vivo studies (36-46). It also provides evidence of its value in recognizing myocardial hemorrhage and impending wall rupture, thus allowing a window of interventional opportunity in this often catastrophic event $(8,38,47-55)$.

The aim of this study was to evaluate, by means of $M R I$, in subacute myocardial infarction, if the different pharmacological strategies of GUSTO $V$ reperfusion protocol i.e. full dose reteplase vs half dose reteplase plus full dose abciximab ( $R+A b c x)$, display different effects on volumes and function of the left ventricle (LV), as well as on miocardial infarct size (Mlsz) and MO (29).

\section{SUBJECTS AND METHODS}

From the list of consecutive patients randomized in the GUSTO V study at our Institution, 20 male patients, mean age 58 years range 37-75, were addressed, after written consent, to MRI study in the $4^{\text {th }}$ day of myocar- dial infarction.

Although selected from a progressive list, in agreement with the criteria of GUSTO V (29), the grid of MRI studies was created to fulfil the following criteria: age matched patients affected by anterior and posterior myocardial infarctions, age matched patients treated with reteplase or $\mathrm{R}+\mathrm{Abcx}$. The grid was thus composed of: 5 anterior treated with reteplase, 5 anterior treated with $\mathrm{R}+\mathrm{Abcx}, 5$ inferior treated with reteplase, 5 inferior treated with $\mathrm{R}+\mathrm{Abcx}$. All groups had an identical pain to fibrinolytic therapy time. All patients had clinically uncomplicated and apparently reperfused myocardial infarction.

Statistical evaluation was made with SPSS 13.0 software.

\section{Magnetic resonance protocol}

Examinations were performed on a Somatom Vision 1.5T scanner (Siemens Erlangen Germany) and analyzed with the built-in Numaris cardiac software.

After initial ECG triggered turbo-flash scouts in axial and in double oblique direction, STIR T2 breath hold $10 \mathrm{~mm}$ thickness images, were obtained in four chambers and in consecutive contiguous short axis views (SAX), encompassing the whole LV from the base to the apex. A complete three dimensional (3D) STIR T2 study was then created by assembling all base to apex slices in a 3D package, from which LV end diastolic volume (EDV) and LV end diastolic mass could be calculated. STIR T2 hyperintense signal was then manually outlined in each SAX slice and subsequently 3D reconstructed to obtain myocardial infarct size (Mlsz), representative of ischemic/infarcted myocardium. Mlsz was expressed as a percent of the entire LV mass (Fig. 1). In order to quantify the degree of hypersignal level, a circular region of interest (ROI) of $0.5 \mathrm{~cm}$ diameter was positioned in the center of STIR T2 hyperintense area and the value was compared with a similar $\mathrm{ROI}$ positioned in a region remote from the site of infarction. A dimensionless value, STIR Intensity ratio, was obtained to represent the signal intensity on myocardial infarction.

A bolus of $0.2 \mathrm{mmol}$ Gd-DTPA per $\mathrm{kg}$ body weight (Magnevist, Schering-AG, Berlin, Germany) was then injected. The same SAX positions of the STIR study were repeated with 2D-flash cine sequences $(2 \mathrm{~d}-\mathrm{fl})$. By assembling base to apex contiguous SAX $2 \mathrm{~d}$-fl cineloops, 


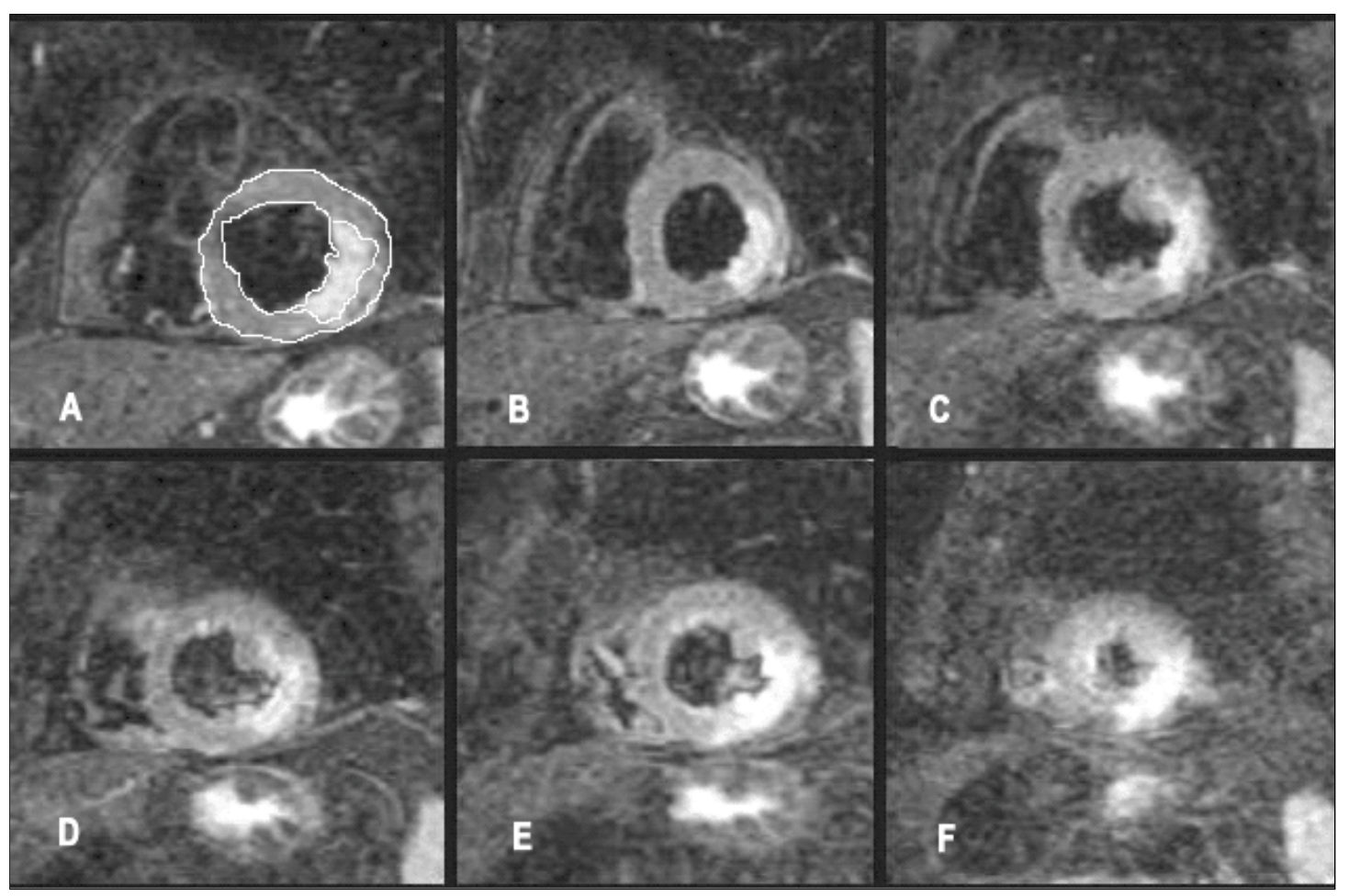

Fig. 1 - From base (A) to apex (F) STIR T2 contiguous slices. Endocardial and epicardial contours define the myocardial slice area from which a $3 D$ quantification of $L V$ mass can be obtained. Similarly contour of hypersignal area $(A)$ applied to all slices, creates the MIsz, expressed in \% of $L V$ mass.

a new 3D study was created from which EDV and ejection fraction (EF) were calculated as habitually done in cardiac MRI procedure.

As all $\mathrm{T} 1$ sequences, also $2 \mathrm{~d}-\mathrm{fl}$ is fit to visualize myocardial signal void in the presence of MO with the limitation of less contrasted images compared to more dedicated T1 sequences, but with the advantage of being able to follow the MO dynamically during systole (8). In order to visualize only persistent $\mathrm{MO}, 2 \mathrm{~d}$-fl acquisition started five minutes after Gd injection. Since delineation and quantification of small MO was practically unfeasible, MO was visually estimated and classified as: not present (group 1), small subendocardial (group 2 ), and large or transmural (group 3).

Due to the limited time allowed for each patient, potentially unstable in day four after myocardial infarction, to the limited contrast gain in late enhancement imaging of our present scanner, to the main goal of this study i.e. to discover differences in volumes and EF, and also to the still incomplete standardization of this technique for quantification of infarct size, (56) late enhancement quantification of infarct size was not performed. Thus each study could be contained in 30 minutes, the time allowed by the Ethical Committee of our Hospital for the study of this type of patients.

The list of patients, treatment and measurement performed is reported in Table I.

\section{RESULTS}

Table I sets out the list of patients with individual measurements; in Table II the descriptive statistics in both types of treatment; and in Table III the descriptive statistics divided by drug regimen and site of myocardial infarction.

Tables from IV to VII show the results of paired t-test (2 tailed significance) for the two different regimens of therapy.

As evident, mean values of Mlsz, EF, Intensity Ratio and EDV, were not statistically different in patients treated with reteplase and in those treated with $\mathrm{R}+\mathrm{Abcx}$. Neither a further grouping for site of myocardial infarction provided additional differences. In spite of this, mean value of EF in Abciximab was only slightly depressed but clearly higher than that of the reteplase group. So when a correlation was attempted with EF and the other measures evaluated, it became clear that 
TABLE I - LIST OF PATIENTS WITH INDIVIDUAL MEASUREMENTS

\begin{tabular}{|c|c|c|c|c|c|c|c|c|}
\hline Name & Age & MI & Drug & $\begin{array}{c}\text { STIR } \\
\text { 3D MIsz \% }\end{array}$ & $\begin{array}{c}\text { 2d-fl } \\
\text { 3D EF \% }\end{array}$ & $\begin{array}{c}\text { STIR } \\
\text { Intensity ratio }\end{array}$ & $\begin{array}{c}\text { 2d-fl } \\
\text { 3D EDV mL }\end{array}$ & $\begin{array}{c}2 d-f l \\
\text { MO 1-2-3 }\end{array}$ \\
\hline G.P. & 48 & Ant. & $\mathrm{R}+\mathrm{Abcx}$ & 31 & 36 & 1.57 & 173 & 1 \\
\hline A.G.C. & 71 & Ant. & $\mathrm{R}+\mathrm{Abcx}$ & 73 & 56 & 1.27 & 131 & 1 \\
\hline O.E. & 67 & Ant. & $\mathrm{R}+\mathrm{Abcx}$ & 13 & 50 & 1.6 & 120 & 2 \\
\hline B.G. & 62 & Ant. & $\mathrm{R}+\mathrm{Abcx}$ & 11 & 67 & 1.87 & 115 & 1 \\
\hline L.C.A. & 60 & Ant. & $R+A b c x$ & 14 & 54 & 1.7 & 136 & 1 \\
\hline S.M. & 53 & Ant. & Reteplase & 19 & 44 & 1.65 & 145 & 2 \\
\hline N.M. & 75 & Ant. & Reteplase & 41 & 26 & 2.2 & 104 & 2 \\
\hline F.G. & 45 & Ant. & Reteplase & 26 & 35 & 1.82 & 237 & 1 \\
\hline F.L. & 59 & Ant. & Reteplase & 24 & 44 & 1.8 & 76 & 2 \\
\hline M.E. & 72 & Ant. & Reteplase & 24 & 43 & 1.5 & 187 & 1 \\
\hline M.C. & 57 & Inf. & $R+A b c x$ & 36 & 34 & 1.98 & 225 & 1 \\
\hline P.D. & 53 & Inf. & $\mathrm{R}+\mathrm{Abcx}$ & 39 & 60 & 1.67 & 149 & 1 \\
\hline A.U. & 73 & Inf. & $\mathrm{R}+\mathrm{Abcx}$ & 17 & 42 & 1.96 & 132 & 3 \\
\hline G.G. & 51 & Inf. & $\mathrm{R}+\mathrm{Abcx}$ & 35 & 56 & 1.39 & 221 & 2 \\
\hline S.G. & 66 & Inf. & $\mathrm{R}+\mathrm{Abcx}$ & 20 & 53 & 1.94 & 93 & 2 \\
\hline G.F. & 48 & Inf. & Reteplase & 22 & 43 & 1.64 & 212 & 3 \\
\hline C.A. & 63 & Inf. & Reteplase & 22 & 45 & 1.75 & 160 & 3 \\
\hline P.S. & 37 & Inf. & Reteplase & 19 & 52 & 1.62 & 140 & 3 \\
\hline S.M. & 37 & Inf. & Reteplase & 17 & 49 & 1.93 & 142 & 1 \\
\hline S.S. & 65 & Inf. & Reteplase & 36 & 31 & 1.5 & 128 & 3 \\
\hline
\end{tabular}

TABLE II - DESCRIPTIVE STATISTICS IN BOTH TYPES OF TREATMENTS

\begin{tabular}{|c|c|c|c|c|c|}
\hline Drug & & Minimum & Maximum & Mean & STD \\
\hline \multirow[t]{5}{*}{$R+A b c x$} & age & 48 & 73 & 60.8 & 8.5 \\
\hline & STIR 3D MIsz \% & 11 & 73 & 28.9 & 18.7 \\
\hline & 2d-fl 3D EF & 34 & 67 & 50.8 & 10.5 \\
\hline & STIR Intensity ratio & 1.27 & 2 & 1.7 & 0.2 \\
\hline & 2d-fl 3D EDVmL & 93 & 225 & 149.5 & 44 \\
\hline \multirow[t]{5}{*}{ Reteplase } & age & 37 & 75 & 55.4 & 13.6 \\
\hline & STIR 3D MIsz \% & 17 & 41 & 25 & 7.7 \\
\hline & 2d-fl 3D EF & 26 & 52 & 41.2 & 8.1 \\
\hline & STIR Intensity ratio & 1.50 & 2.20 & 1.75 & 0.2 \\
\hline & 2d-fl 3D EDVmL & 76 & 237 & 153.1 & 48.3 \\
\hline
\end{tabular}

TABLE III - DESCRIPTIVE STATISTICS DIVIDED BY DRUG REGIMEN

\begin{tabular}{|c|c|c|c|c|c|c|c|}
\hline Drug & MI & & Age & STIR 3D MIsz \% & 2d-fl 3D EF & $\begin{array}{c}\text { STIR } \\
\text { Intensity ratio }\end{array}$ & $\begin{array}{c}\text { 2d-fl } \\
\text { 3D EDV mL }\end{array}$ \\
\hline \multirow[t]{6}{*}{$R+A b c x$} & \multirow[t]{2}{*}{ ant } & mean & 61.6 & 28.4 & 52.6 & 1.6 & 135 \\
\hline & & STD & 8.7 & 26.2 & 11.2 & 0.2 & 22.8 \\
\hline & \multirow[t]{2}{*}{$\inf$} & mean & 60 & 29.4 & 49 & 1.8 & 164 \\
\hline & & STD & 9.3 & 10.1 & 10.7 & 0.3 & 57.6 \\
\hline & \multirow[t]{2}{*}{ Total } & mean & 60.8 & 28.9 & 50.8 & 1.7 & 149.5 \\
\hline & & STD & 8.5 & 18.7 & 10.5 & 0.2 & 44. \\
\hline \multirow{6}{*}{ Reteplase } & \multirow[t]{2}{*}{ ant } & mean & 60.8 & 26.8 & 38.4 & 1.8 & 149.8 \\
\hline & & STD & 12.6 & 8.3 & 7.9 & 0.3 & 64.3 \\
\hline & \multirow[t]{2}{*}{$\inf$} & mean & 50 & 23.2 & 44 & 1.7 & 156.4 \\
\hline & & STD & 13.6 & 7.5 & 8.1 & 0.2 & 33.1 \\
\hline & \multirow[t]{2}{*}{ Total } & mean & 55.4 & 25 & 41.2 & 1.8 & 153.1 \\
\hline & & STD & 13.6 & 7.7 & 8.1 & 0.2 & 48.3 \\
\hline
\end{tabular}


TABLE IV - INFARCT SIZE (MIsz\%) AS \% OF THE WHOLE, THREE DIMENSIONALLY (3D) CALCULATED, MYOCARDIAL MASS

\begin{tabular}{lccc}
\hline $\begin{array}{l}\text { STIR } \\
\text { 3D MIsz \% }\end{array}$ & Mean & Standard Deviation & Sig. (2-tailed) \\
\hline R+Abcx & 28.9 & 18.72 & 0.586 \\
Reteplase & 25.0 & 7.70 & \\
\hline
\end{tabular}

TABLE V - FROM CONTIGUOUS BASE TO APEX CINE 2d-flash SLICES, THREE DIMENSIONAL (3D) EJECTION FRACTION (EF) IS CALCULATED IN BOTH DRUG REGIMENS

\begin{tabular}{lccc}
\hline $\begin{array}{l}\text { 2d-fl } \\
\text { 3D EF }\end{array}$ & Mean & Standard Deviation & Sig. (2-tailed) \\
\hline R+Abcx & 50.80 & 10.51 & 0.035 \\
Reteplase & 41.20 & 8.08 & \\
\hline
\end{tabular}

TABLE VI - RATIO BETWEEN INTENSITY VALUES OBTAINED WITH STIR IMAGES, IN INFARCT AREA AND IN NORMAL MYOCARDIUM, IN BOTH DRUG REGIMENS

\begin{tabular}{lccc}
\hline $\begin{array}{l}\text { STIR } \\
\text { Intensity ratio }\end{array}$ & Mean & Standard Deviation & Sig. (2-tails) \\
\hline R+Abcx & 1.69 & 0.25 & 0.653 \\
Reteplase & 1.74 & 0.22 & \\
\hline
\end{tabular}

TABLE VII - END DIASTOLIC VOLUME (EDV), EXPRESSED IN MILLILITERS(ML) OBTAINED FROM CINE 2D-FLASH (2d-fl) SEQUENCES, IN BOTH DRUG REGIMENS

\begin{tabular}{lccc}
\hline 2d-fl 3D EDVmL & Mean & Standard Deviation & Sig. (2-tailed) \\
\hline R+Abcx & 149.5 & 44.03 & 0.842 \\
Reteplase & 153.1 & 48.36 & \\
\hline
\end{tabular}

the linear regression between EF and MIsz was strongly significant in the reteplase group. In this last, the larger the Mlsz, the lower the EF. This clear and expected correlation was no longer present in $\mathrm{R}+\mathrm{Abcx}$ group with EF completely unrelated to Mlsz (Fig. 2).

Similarly, MO also showed a powerful relation to EF, with the strongest correlation in group 3 of patients,

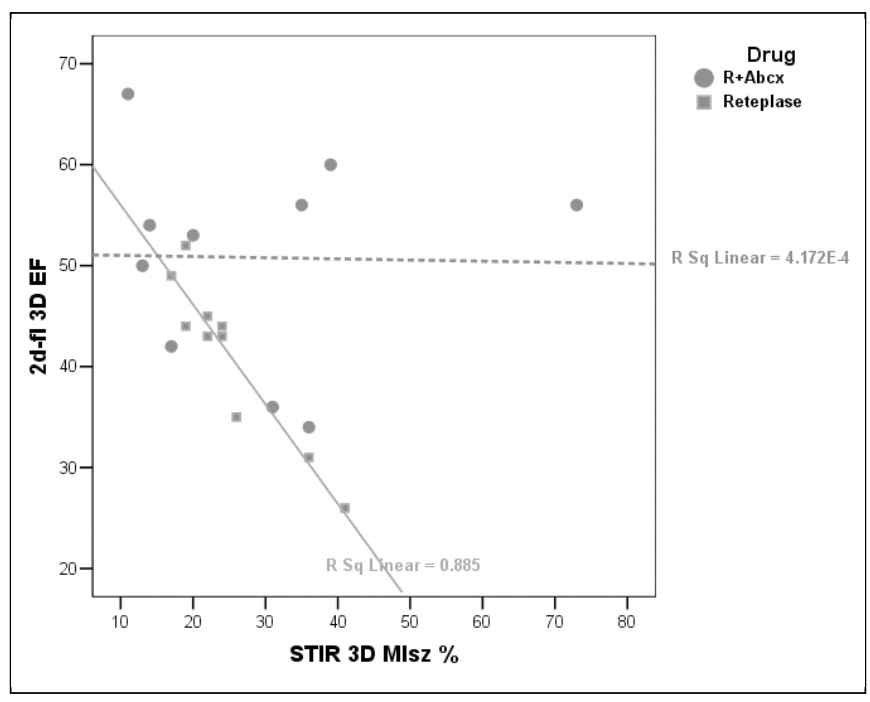

Fig. 2 - Inverse linear regression between infarct size (MIsz\%) ad ejection fraction (2d-fI 3D EF) in both drug regimens. Details in the text.

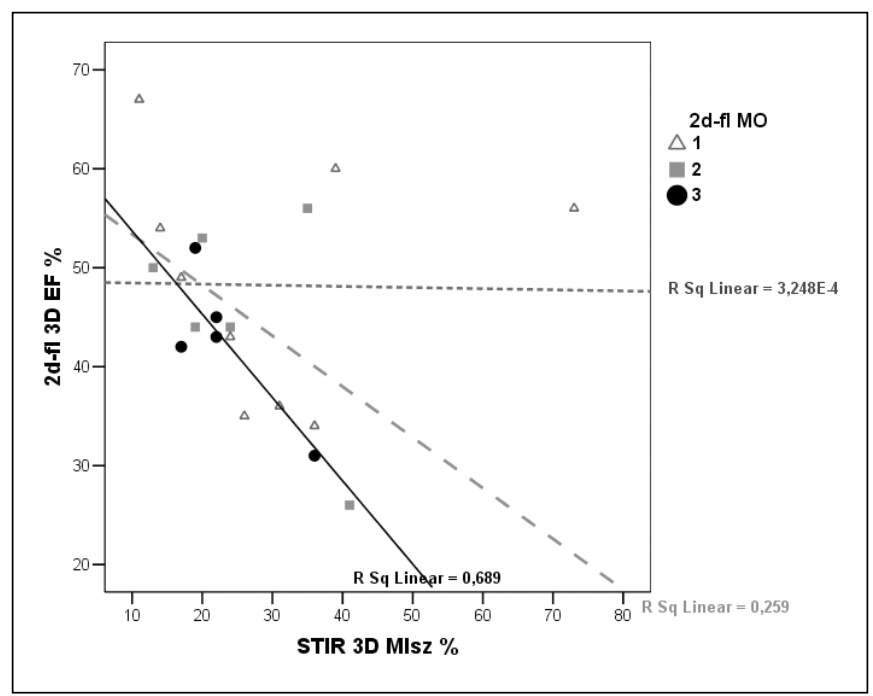

Fig. 3 - Relationship between microvascular obstruction (2d-fl MO) infarct size (MIsz\%) ad ejection fraction (2d-fl 3D EF). 1,2 and 3 represent: no MO, small MO and large MO respectively. Details in the text.

those with the greatest MO areas (Fig. 3).

Large MO (group 3) was present in $25 \%$ of patients: i.e 5 out of 20 . Four of these patients were in the reteplase group whereas small subendocardial (group 2) MO, were uniformly distributed in R+Abcx groups: see Table I.

Of note, two patients of this study died: C.A. and P.S. both for wall rupture, both in the reteplase group and 


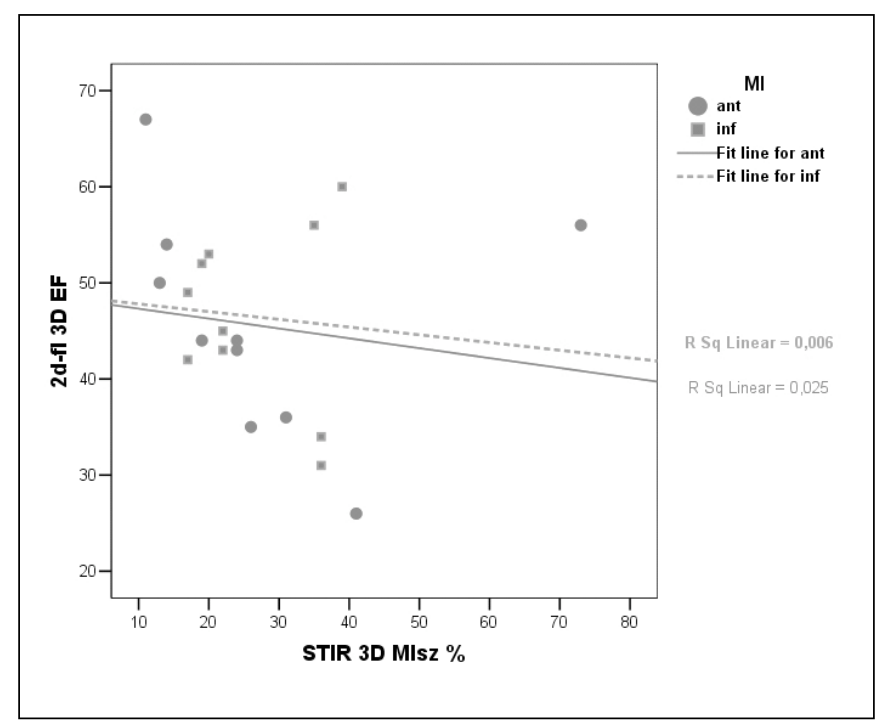

Fig. 4 - Inverse linear regression between infarct size (MIsz\%) ad ejection fraction (2d-fl $\mathbf{3} \boldsymbol{D} \mathbf{E F})$ according to the site of myocardial infarction: anterior (Ant.) or inferior (Inf.). Details in the text. with severe (group 3) MO. The first patient who died in day five, was the object of a previous publication (8). The second suddenly died at home 7 days after uncomplicated myocardial infarction.

Finally, no significant correlations could be found when patients were grouped according to the site of myocardial infarction (Fig. 4).

\section{DISCUSSION}

The first consideration regards EF. As already known, $M R I$ 3D reconstruction of the LV carries a small variability so that also a limited population can be sufficient to disclose differences not revealed by echocardiography (57-62). This is also the case of this 20 patient study, in which mean EF in R+Abcx patients was clearly higher, though with weak significance, compared to the reteplase group. This occurred despite similar Mlsz and intensity ratio, indicating that different degrees of cell

Fig. 5 - Short axis STIR image of the left ventricle $(\boldsymbol{A})$ and the corresponding macroscopic autoptic specimen (C). Subendocardial void of signal in $A$ corresponds to hemorrhagic tissue in $C$, while hypersignal in A corresponds to edema in $C$. (D) small red cells dominate the center of hemorrhagic area (dark subendocardium in C). (B) in the area of edema (white area in C) proceeding from the inner (right-bottom) to the outer (left-top) plane: the number of unbroken myocites progressively increases while the interstitial space progressively reduces.

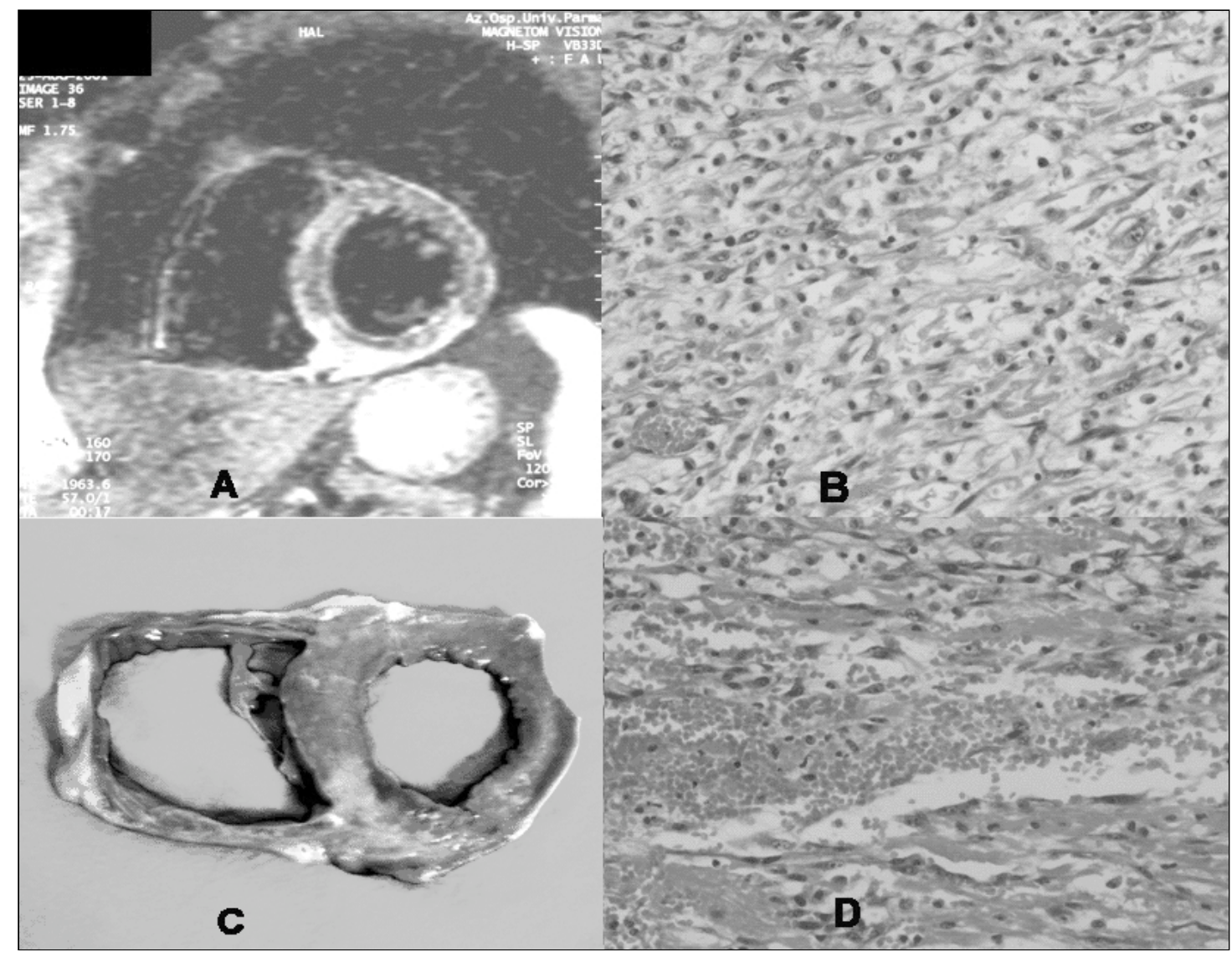




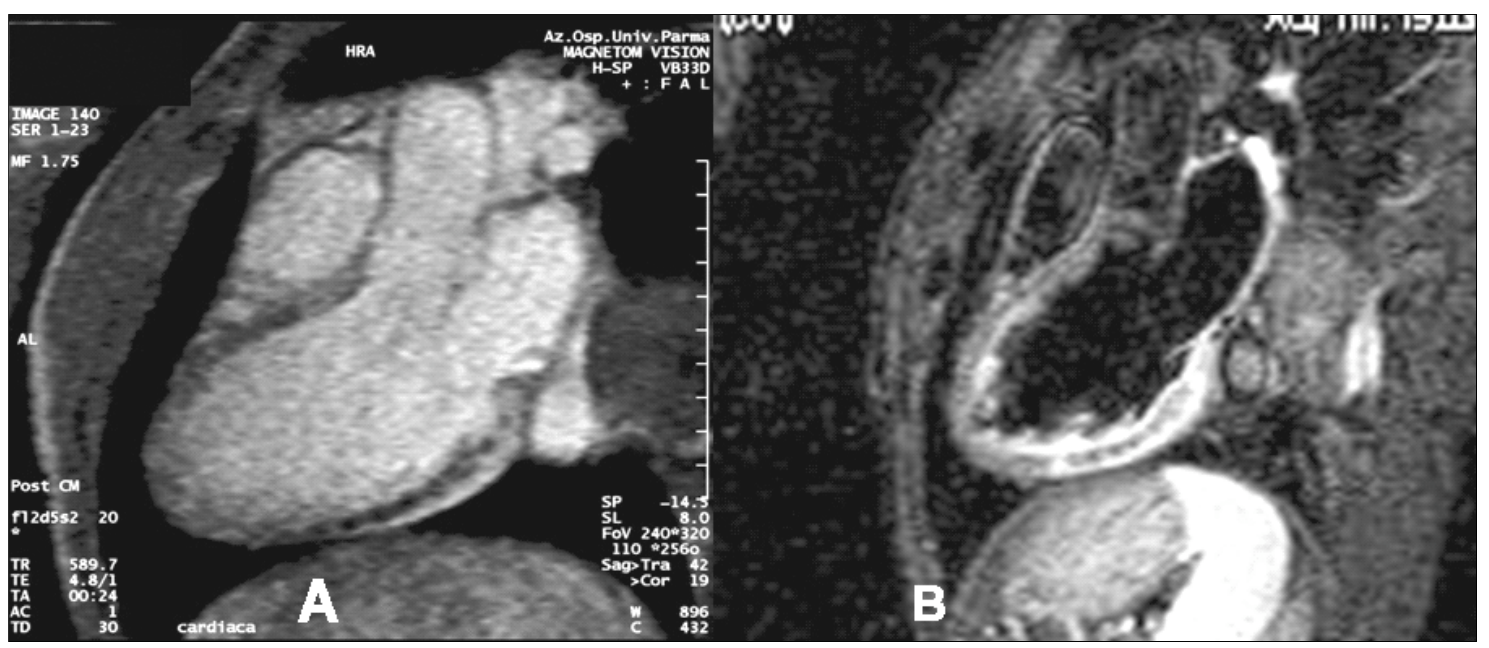

Fig. 6 - Long axis images of the left ventricle in cine $2 d$-flash $(\boldsymbol{A})$ and in STIR T2 sequence (B).

Both indicate the presence of MO, STIR image also suggesting the hemorrhagic nature of MO. Complete description in the text.

damage may be represented by similar STIR T2 signal, which thus seems unable to distinguish irreversible necrotic from reversible viable myocardium. This latter is the prevalent condition in Mlsz of patients treated with $\mathrm{R}+\mathrm{Abcx}$.

The traditional onion configuration of myocardial ischemia and infarction suggests that the outer layers are less damaged than the inner myocardium. Under these circumstances with increasing Mlsz a progressive impairment of the LV with lowering EF should be expected. In the reteplase group in fact all this happened, as represented by the clear inverse relation between Mlsz and EF. This was the result of epicardial fibrinolysis, which though successful, could not prevent the development of MO. This was related, in our study with equivalent pain to treatment time between groups (63) to the extent of Mlsz more than the success of epicardial trombolysis.

The above considerations were furthermore confirmed by the opposite behaviour observed in R+Abcx patients where not only epicardial but also microvascular vessels were pharmacologically preserved. In these patients despite unchanged Mlsz compared to reteplase, the inverse relationship of Figure 2 was completely lost and almost no MO occurred.

A second consideration arises from STIR T2- imaging of myocardial infarction.

Almost contemporaneously some years ago, two different works indicated that T2 weighted (64) and T1 weighted sequences (39) were able to define infarct areas with good correspondence with the infarct size expressed by Thallium irreversible defect. In experimental comparison however (65), infarct areas seemed more accurately represented by T1 compared to those, slightly overestimated, obtained with T2 sequences. Nonetheless the same images also indicated that T2weighted could detect subendocardial void of signal not visible in T1 sequence, indicating that two different tissue were at the same time present in that infarct area, both well detected by T2 approach. This closely calls $\mathrm{MRI}$ experimental data which indicate that in the same infarct area, irreversibly damaged myocites with patent microcirculation and irreversibly damaged myocytes with occluded microcirculation may coexist (12).

Since then, both T2 (66-68) and T1 late enhancement imaging have been utilized to estimate infarct size, T1weighted largely dominating the scene (36, 39, 69-92).

In spite of this, some limitations suggest that beyond the clear experimental and clinical evidence of late enhancement usefulness, the exact quantification of infarct size requires further technological, procedural and methodological steps to be completely defined $(56,68,74)$.

In addition, void of signal in T2 images most likely indicates hemorrhagic tissue, currently a prevalent domain of T2 imaging (93-96).

A comprehensive illustration of the above considerations is reproduced in the cases: C.A. Figure 5 whose imaging of wall rupture as been object of a previous publication (8) and P.S. Figure 6 suddenly dead for wall rupture as previously reported.

Figure 5 shows C.A. STIR T2 short axis slice with clear evidence of transmural hyperenhancement of the inferior wall surrounding a subendocardial void of signal 
(A). This respectively corresponds to: oedema and subendocardial haemorrhage in the macroscopic autoptic specimen (B). The histological aspect of those layers indicate subendocardial red blood cells predominance (D) and in (C) the extensive loss of myocytes in the confining zone near the hemorrhagic endocardium, progressively replaced in the outer layers by unbroken myocytes and parallel reduction of "expanded" interstitium. This last happened without a clear modification of signal intensity in hyperenhanced area of $A$ Thus similar or contiguous levels of T2 intensity, represents different degrees of cell injure as already outlined in previous MRI studies on ischemia necrosis hemorrhage and healing tissue (97)

In Figure 6 is represented the second case of wall rupture: P.S. A long axis $2 \mathrm{~d}$-fl after Gadolinium injection clearly demonstrate the presence of a long $\mathrm{MO}$ extended from the base to the subepicardial inferior distal wall. Both 2d-fl (A) and STIR T2 (B) images were able to identify the presence of severe MO, STIR T2 also suggesting the haemorrhagic characteristics of $\mathrm{MO}$, and $2 \mathrm{~d}$-fl allowing to follow $\mathrm{MO}$ dynamically during systole, thus indicating its threatening extension towards the epicardium.

\section{CONCLUSION}

$\mathrm{R}+\mathrm{Abcx}$ prevents $\mathrm{MO}$ : compared to traditional fibrinolytic therapy, this allow a better LV function and most likely an improved long term survival.

Extensive $\mathrm{MO}$ was present and well recognized in $25 \%$ of all cases, $80 \%$ of which fall in the Reteplase group of treatment.

The combination of T1 dynamic 2d-flash cine and STIR T2 sequences may allow recognition and tissue characterisation of $\mathrm{MO}$ also suggesting the presence of impending ruptures.

Address for correspondence:

Antonello Zoni, MD

Heart Department

University Hospital of Parma

Via Gramsci, 14

43100 Parma - Italy

antonello.zoni@libero.it

\section{REFERENCES}

1. Neumann FJ. Optimization of microvascular reperfusion in acute myocardial infarction. European Heart Journal Supplements 2001; 3 (Suppl A), A21-5.

2. Kaul S, Ito H. Microvasculature in acute myocardial ischemia: Part I and part II evolving concepts in pathophysiology, diagnosis, and treatment. Circulation 2004; 109: 146-9: 310-5.

3. Christiansen JP, Leong-Poi H, Klibanov AL, et al. Noninvasive imaging of myocardial reperfusion injury using leukocyte-targeted contrast echocardiography circulation 2002; 105: 1764-7.

4. Ragosta M, Camarano GP, Kaul S, et al. Microvascular integrity indicates myocellular viability in patients with recent myocardial infarction: New insights using myocardial contrast echocardiography. Circulation 1994; 89: 2562-9.

5. Ito $\mathrm{H}$, Okamura A, Iwakura K, et al. Myocardial perfusion patterns related to thrombolysis in myocardial infarction perfusion grades after coronary angioplasty in patients with acute anterior wall myocardial infarction. Circulation 1996; 93: 1993-9.

6. Asanuma T, Tanabe K, Ochiai K, et al. Relationship between progressive microvascular damage and intramyocardial hemorrhage in patients with reperfused anterior myocardial infarction: Myocardial contrast echocardiographic study. Circulation 1997; 96: 448-53.

7. Reffelmann T, Kloner RA. Anatomic no reflow during reperfusion in the rabbit. AJP - Heart 2002; 283: 1099107.

8. Zoni A, Arisi A, Corradi D, et al. Magnetic resonance imaging of impending left ventricular rupture after acute myocardial infarction. Circulation 2003; 108: 498-9.

9. Henriques JPS, Zijlstra F, Ottervanger JP, et al. Incidence and clinical significance of distal embolization during primary angioplasty for acute myocardial infarction. European Heart Journal 2002; 23: 1112-7.

10. Davies MJ , Thomas AC, Knapman PA, et al. Intramyocardial platelet aggregation in patients with unstable angina suffering sudden ischemic cardiac death. Circulation 1986; 73: 418-27. 
11. Frink RJ, Rooney PA, Trowbridge JO, et al. Coronary thrombosis and platelet/fibrin microemboli in death associated with acute myocardial infarction. Br Heart J 1988; 59: 196-200.

12. Rochitte CE, Lima JAC, Bluemke DA, et al. Magnitude and time course of microvascular obstruction and tissue injury after acute myocardial infarction. Circulation 1998; 98: 1006-14.

13. Bremerich J, Wendland MF, Arheden H, et al. Microvascular injury in reperfused infarcted myocardium: Noninvasive assessment with contrast-enhanced echoplanar magnetic resonance imaging. J Am Coll Cardiol 1998; 32: 787-93.

14. Reffelmann T. No-reflow phenomenon persists long-term after ischemia/reperfusion in the rat and predicts infarct expansion circulation. 2003; 108: 2911-7.

15. Jugdutt BI. Ventricular remodeling after infarction and the extracellular collagen matrix: When is enough enough? Circulation 2003; 108: 1395-403.

16. Wu KC, Zerhouni EA, Judd RM. Prognostic significance of microvascular obstruction by magnetic resonance imaging in patients with acute myocardial infarction. Circulation 1998; 97: 765-72.

17. Limbruno U, Micheli A, De Carlo M, et al. Mechanical prevention of distal embolization during primary angioplasty: Safety, feasibility, and impact on myocardial reperfusion. Circulation 2003; 108: 171-6.

18. Sangiorgi G, Colombo A. Embolic protection devices. Heart 2003; 89: 990-2.

19. Piana RN, Paik GY, Moscucci M, et al. Incidence and treatment of "no reflow" after percutaneous coronary intervention. Circulation 1994; 89: 2514-8.

20. Ishihara $\mathrm{M}$, Sato $\mathrm{H}$, Tateishi $\mathrm{H}$, et al. Attenuation of the no-reflow phenomenon after coronary angioplasty for acute myocardial infarction with intracoronary papaverine. Am Heart J 1996; 132: 959-63.

21. Neumann F-J, Kenngott S, Gawaz M, Schomig M. Procoagulant inflammatory responses of monocytes after direct balloon angioplasty in acute myocardial infarction. Am J Cardiol 1998; 82: 938-42.

22. Taniyama $\mathrm{Y}$, Ito $\mathrm{H}$, Iwakura $\mathrm{K}$, et al. Beneficial effect of intracoronary verapamil on microvascular and myocardial salvage in patients with acute myocardial infarction. J Am Coll Cardiol 1997; 30: 1193-9.

23. Meisel SR, Shapiro H, Radnay J, et al. Increased expression of neutrophil and monocyte adhesion molecules LFA- 1 and Mac- 1 and their ligand ICAM-1 and VLA-4 throughout the acute phase of myocardial infarction: Possible implications for leukocyte aggregation and microvascular plugging. J Am Coll Cardiol 1998; 31: 120-5.

24. Neumann F-J, Blasini R, Schmitt $C$ et al. Effect of glycoprotein Ilb/IIla receptor blockade on recovery of coronary flow and left ventricular function after the placement of coronary-artery stents in acute myocardial infarction. Circulation 1998; 98: 2695-701.

25. Mahaffey KW, Puma JA, Barbagelata A, et al. Adenosine as an adjunct to thrombolytic therapy for acute myocardial infarction: Results of a multicenter, randomized, placebo-controlled trial-the Acute Myocardial Infarction STudy of ADenosine (AMISTAD) trial. J Am Coll Cardiol 1999; 34: 1171-20.

26. Ito $\mathrm{H}$, Taniyama $\mathrm{Y}$, Iwakura $\mathrm{K}$, et al. Intravenous nicorandil can preserve microvascular integrity and myocardial viability in patients with reperfused anterior wall myocardial infarction. J Am Coll Cardiol 1999; 33: 654-60.

27. de Lemos JA, Antman EM, Gibson CM, et al. Abciximab improves both epicardial flow and myocardial reperfusion in ST-elevation myocardial infarction: Observations from the TIMI 14 trial. Circulation 2000; 101: 239-43.

28. Sato T, Sasaki N, O'Rourke B, et al. Nicorandil, a potent cardioprotective agent, acts by opening mitochondrial ATP-dependent potassium channels. J Am Coll Cardiol 2000; 35: 514-8.

29. The GUSTO V Investigators. Reperfusion therapy for acute myocardial infarction with fibrinolytic therapy or combination low dose fibrinolytic therapy and platelet glycoprotein Ilb/Illa inhibition: The GUSTO V Trial Lancet 2001; 357: 1905-14.

30. Lincoff AM, Califf RM, van de Werf F, et al., for the GUSTO V Investigators. Mortality at 1 year with combination platelet glycoprotein Ilb/IIla inhibition and reduced-dose fibrinolytic therapy versus conventional fibrinolytic therapy for acute myocardial infarction: The GUSTO $V$ randomized trial. JAMA 2002; 288: 2130-5.

31. Sakuma T, Leong-Poi H, Fisher NG, et al. Further insights into the "no-reflow" phenomenon after primary angioplasty in acute myocardial infarction: The role of microthromboemboli. J Am Soc Echocardiogr 2003; 16: 15-21.

32. Galiuto L. Optimal therapeutic strategies in the setting of post-infarct no reflow: The need for a pathogenetic classification. Heart 2004; 90: 123-5.

33. Steen H, Lehrke S, Wiegand UKH. Very early cardiac magnetic resonance imaging for quantification of myocardial tissue perfusion in patients receiving tirofiban before percutaneous coronary intervention for ST-elevation myocardial infarction. Am Heart J 2005; 149: 564-4.

34. Yamamuro A. Coronary flow velocity pattern immediately after percutaneous coronary intervention as a predictor of complications and in-hospital survival after acute myocardial infarction. Circulation 2002; 106: 3051-6.

35. Furber AP, Prunier F, Cuong H, Nguyen P, et al. Coronary blood flow assessment after successful angioplasty for acute myocardial infarction predicts the risk of long-term cardiac events. Circulation 2004; 110: 3527-33.

36. Rogers WJ, Kramer CM, Geskin G, et al. Early contrastenhanced MRI predicts late functional recovery after 
reperfused myocardial infarction. Circulation 1999; 99: 744-50.

37. Rochitte CE, Kim RJ, Hillenbrand HB, et al. Microvascular integrity and the time course of myocardial sodium accumulation after acute infarction. Circ Res 2000; 87: 648-55.

38. Miller $\mathrm{S}$, Helber $\mathrm{U}, \mathrm{Kramer} U$, et al. Subacute myocardial infarction: Assessment by STIR T2-weighted MR imaging in comparison to regional function. Magnetic Resonance Materials in Physics, Biology and Medicine 2001; 13: 8-14.

39. Ramani K, Judd RM, Holly TA, et al. Contrast magnetic resonance imaging in the assessment of myocardial viability in patients with stable coronary artery disease and left ventricular dysfunction. Circulation 1998; 98: 2687-94.

40. Gerber BL, Rochitte CE, Melin JA, et al. Microvascular obstruction and left ventricular remodeling early after acute myocardial infarction. Circulation 2000; 101: 2734-41.

41. Kramer CM, Rogers WJ, Mankad S, et al. Contractile reserve and contrast uptake pattern by magnetic resonance imaging and functional recovery after reperfused myocardial infarction. J Am Coll Cardiol 2000; 36: 6.

42. Miller S, Schicka F, Scheule AM, et al. Conventional high resolution versus fast T2-weighted MR imaging of the heart: Assessment of reperfusion induced myocardial injury in an animal model. Magn Reson Imaging 2000; 18: 1069-77.

43. Gerber BL, Rochitte CE, Bluemke DA, et al. Relation between Gd-DTPA contrast enhancement and regional inotropic response in the periphery and center of myocardial infarction. Circulation 2001; 104: 998-1004.

44. Taylor AJ, Al-Saadi N, Abdel-Aty H. Detection of acutely impaired microvascular reperfusion after infarct angioplasty with magnetic resonance imaging. Circulation 2004; 109: 2080-5.

45. ACCF/AHA Clinical competence statement on cardiac imaging with computed tomography and magnetic resonance. J Am Coll Cardiol 2005; 46: 2.

46. Pennell DJ, Sechtem UP, Higgins CB, et al. Clinical indications for cardiovascular magnetic resonance: Consensus panel report. Eur Heart J 2004; 25: 1940-65.

47. Ito H, Tomooka $\mathrm{T}$, Sakai $\mathrm{N}$, et al. Lack of myocardial perfusion immediately after successful thrombolysis: A predictor of poor recovery of left ventricular function in anterior myocardial infarction. Circulation 1992; 85: 1699-705.

48. Schwitter J, Saeed M, Wendland MF, et al. Influence of the severity of myocardial injury on the distribution of macromolecules: Extra versus intra-vascular gadoliniumbased MR contrast agents. J Am Coll Cardiol 1997; 30: 1086-94.
49. Wu KC, Kim RJ, Bluemke DA, et al. Quantification and time course of microvascular obstruction by contrast-enhanced echocardiography and magnetic resonance imaging following acute myocardial infarction and reperfusion. J Am Coll Cardiol 1998; 32: 1756-64.

50. Wu KC, Zerhouni EA, Judd RM. Prognostic significance of microvascular obstruction by magnetic resonance imaging in patients with acute myocardial infarction. Circulation 1998; 97: 765-72.

51. Bremerich J, Wendland MF, Arheden H. Microvascular injury in reperfused infarcted myocardium: Noninvasive assessment with contrast-enhanced echoplanar magnetic resonance imaging. J Am Coll Cardiol 1998; 32: 787-93.

52. Saeed M, van Dijke CF, Mann JS, et al. Histologic confirmation of microvascular permeability to macromolecular MR contrast medium in reperfused myocardial infarction. J Magn Reson Imaging 1998; 8: 561-7.

53. Ochiai K, Shimada T, Murakami Y, et al. Hemorrhagic myocardial infarction after coronary reperfusion detected in vivo by magnetic resonance imaging in humans: Prevalence and clinical implications. J Cardiovasc Magn Reson 1999; 1: 247-56.

54. Miller S, Schicka F, Scheuleb AM. Conventional high resolution versus fast T2-weighted MR imaging of the heart: Assessment of reperfusion induced myocardial injury in an animal model. Magn Reson Imaging 2000; 18: 1069-77.

55. Lesser JR, Johnson K, Lindberg JL, et al. Myocardial rupture, microvascular obstruction, and infarct expansion: Elucidation by cardiac magnetic resonance. Circulation 2003; 108: 116-7.

56. Ibrahim T, Nekolla SG, Hörnke M, et al. Quantitative measurement of infarct size by contrast-enhanced magnetic resonance imaging early after acute myocardial infarction. J Am Coll Cardiol 2005; 45: 544-52.

57. Bottini P, Carr A, Prisant L, Flickinger F, Allison J, Gottdiener J. Magnetic resonance imaging compared to echocardiography to assess left ventricular mass in the hypertensive patient. Am J Hypertens 1995; 8: 221-2.

58. Bellenger NG, Francis JM, Davies LC, Coats AJS, Pennell DJ. Establishment and performance of a magnetic resonance cardiac function clinic. J Cardiovasc Magn Reson 1999; 1: 323-30.

59. Bellenger NG, Davies LC, Francis JM, Coats ACS, Pennell DJ. Reduction in sample size for studies of remodeling in heart failure by the use of cardiovascular magnetic resonance. J Cardiovasc Magn Reson 2000; 2: 271-8.

60. Salton CJ, Chuang ML, O'Donnell CJ, et al. Gender differences and normal left ventricular anatomy in an adult population free of hypertension. A cardiovascular magnetic resonance study of the Framingham Heart Study Offspring Cohort. J Am Coll Cardiol 2002; 39: 1055-60. 
61. Grothues F, Smith GC, Moon JC, et al. Comparison of interstudy reproducibility of cardiovascular magnetic resonance with two-dimensional echocardiography in normal subjects and in patients with heart failure or left ventricular hypertrophy. Am J Cardiol 2002; 90: 29-34.

62. Bellenger NG, Swinburn JMA, Rajappan K, et al. Cardiac remodelling in the era of aggressive medical therapy: Does it still exist? Int J Cardiol 2002; 83: 217-25.

63. Tarantini G, Cacciavillani L, Corbetti F, et al. Duration of ischemia is a major determinant of transmurality and severe microvascular obstruction after primary angioplasty. A study performed with contrast-enhanced magnetic resonance. J Am Coll Cardiol 2005; 46: 1229-35.

64. Lim TH, Hong M, Lee JS, et al. Novel application of breath-hold turbo spin-echo T2 MRI for detection of acute myocardial infarction. J Magn Reson Imag 1997; 7: 966.

65. Pislaru SV, Ni Y, Pislaru C, et al. Noninvasive measurements of infarct size after thrombolysis with a necrosisavid MRI contrast agent. Circulation 1999; 99: 690-6.

66. Miller S, Schicka F, Scheule AM, et al. Conventional high resolution versus fast T2-weighted MR imaging of the heart: Assessment of reperfusion induced myocardial injury in an animal model. Magn Reson Imaging 2000; 18: 1069-77.

67. Miller $S$, Helber $U$, Kramer U, et al. Subacute myocardial infarction: Assessment by STIR T2-weighted MR imaging in comparison to regional function. Magnetic Resonance Materials in Physics, Biology and Medicine 2001; 13: 8-14.

68. Abdel-Aty H, Zagrosek A, Schulz-Menger J, et al. Delayed enhancement and T2-weighted cardiovascular magnetic resonance imaging differentiate acute from chronic myocardial infarction. Circulation 2004; 109: 2411-6.

69. Kim RJ, Chen EL, Lima JA, Judd RM. Myocardial GdDTPA kinetics determine MRI contrast enhancement and reflect the extent and severity of myocardial injury after acute reperfused infarction. Circulation 1996; 94: 3318-26.

70. Kim RJ, Fieno DS, Parrish TB, et al. Relationship of MRI delayed contrast enhancement to irreversible injury, infarct age, and contractile function. Circulation 1999; 100 : 1992-2002.

71. Saeed M, Bremerich J, Wendland MF, et al. Reperfused myocardial infarction as seen with use of necrosis-specific versus standard extracellular MR contrast media in rats. Radiology 1999; 213: 247-57.

72. Fieno DS, Kim RJ, Chen EL, et al. Contrast-enhanced magnetic resonance imaging of myocardium at risk: Distinction between reversible and irreversible injury throughout infarct healing. J Am Coll Cardiol 2000; 36: 1985 .
73. Simonetti OP, Kim RJ, Fieno DS, et al. An improved MR imaging technique for the visualization of myocardial infarction. Radiology 2001; 218: 215-23.

74. Hillenbrand HB, Kim RJ, Parker MA, et al. Early assessment of myocardial salvage by contrast-enhanced magnetic resonance imaging. Circulation 2000; 102: 1678-83.

75. Sandstede JJ, Lipke C, Beer M, et al. Analysis of firstpass and delayed contrast-enhancement patterns of dysfunctional myocardium on MR imaging: Use in the prediction of myocardial viability. AJR Am J Roentgenol 2000; 174: 1737-40.

76. Kim RJ, Wu E, Rafael A, et al. The use of contrast-enhanced magnetic resonance imaging to identify reversible myocardial dysfunction. N Engl J Med 2000; 343: 1445-53.

77. Oshinski JN, Yang Z, Jones JR, et al. Imaging time after Gd-DTPA injection is critical in using delayed enhancement to determine infarct size accurately with magnetic resonance imaging. Circulation 2001; 104: 2838-42.

78. Wu E, Judd RM, Vargas JD, et al. Visualisation of presence, location, and transmural extent of healed $Q$-wave and non-Q-wave myocardial infarction. Lancet 2001; 357: $21-8$

79. Choi KM, Kim RJ, Gubernikoff G, et al. Transmural extent of acute myocardial infarction predicts long-term improvement in contractile function. Circulation 2001; 104: 1101-7.

80. Mahrholdt H, Wagner A, Holly TA, et al. Reproducibility of chronic infarct size measurement by contrast-enhanced magnetic resonance imaging. Circulation 2002; 106: 2322-7.

81. Rehwald WG, Fieno DS, Chen EL, et al. Myocardial magnetic resonance imaging contrast agent concentrations after reversible and irreversible ischemic injury. Circulation 2002; 105: 224-9.

82. Barkhausen J, Ebert W, Debatin JF, Weinmann HJ. Imaging of myocardial infarction: Comparison of Magnevist and gadophrin-3 in rabbits. J Am Coll Cardiol 2002; 39: 1392-8.

83. Gerber BL, Garot J, Bluemke DA, et al. Accuracy of contrast-enhanced magnetic resonance imaging in predicting improvement of regional myocardial function in patients after acute myocardial infarction. Circulation 2002; 106: 1083-9.

84. Klein C, Nekolla SG, Bengel FM, et al. Assessment of myocardial viability with contrast-enhanced magnetic resonance imaging: Comparison with positron emission tomography. Circulation 2002; 105: 162-7.

85. Petersen SE, Horstick G, Voigtlander T, et al. Diagnostic value of routine clinical parameters in acute myocardial infarction: A comparison to delayed contrast enhanced magnetic resonance imaging. Delayed enhancement and routine clinical parameters after myocardial infarction. Int 
J Cardiovasc Imaging 2003; 19: 409-16.

86. Martin TN, Groenning BA, Steedman T, et al. A single troponin I concentration measured 12 hours after onset of chest pain accurately reflects infarct size as measured by gadolinium-DTPA late enhancement magnetic resonance imaging. J Am Coll Cardiol 2003; 41: 380-1.

87. Kuhl HP, Beek AM, van der Weerdt AP, et al. Myocardial viability in chronic ischemic heart disease: Comparison of contrast-enhanced magnetic resonance imaging with (18)F-fluorodeoxyglucose positron emission tomography. J Am Coll Cardiol 2003; 41: 1341-8.

88. Knuesel PR, Nanz D, Wyss C, et al. Characterization of dysfunctional myocardium by positron emission tomography and magnetic resonance. Circulation 2003; 108: 1095-100.

89. Beek AM, Kuhl HP, Bondarenko O, et al. Delayed contrast-enhanced magnetic resonance imaging for the prediction of regional functional improvement after acute myocardial infarction. J Am Coll Cardiol 2003; 42: 895-901.

90. Wagner A, Mahrholdt H, Holly TA, et al. Contrast-enhanced MRI and routine single photon emission computed tomography (SPECT) perfusion imaging for detection of subendocardial myocardial infarcts: An imaging study. Lancet 2003; 361: 374-9.

91. Kitagawa K, Sakuma H, Hirano T, et al. Acute myocardial infarction: Myocardial viability assessment in pa- tients early thereafter comparison of contrast-enhanced MR imaging with resting (201)TI SPECT. Single photon emission computed tomography. Radiology $2003 ; 226: 138-44$.

92. Lund GK, Stork A, Saeed M, et al. Acute myocardial infarction: Evaluation with first-pass enhancement and delayed enhancement MR imaging compared with TI 201SPECT imaging. Radiology 2004; 232: 49-57.

93. De Roos A, Van Rossum AC, Van der Wall EE, et al. Reperfused and non reperfused myocardial infarction: Potential of gadolinium DTPA enhanced MR imaging. Radiology 1989; 172: 717-20.

94. Eichstaedt HW, Felix R, Dougherty FC, et al. Magnetic resonance imaging in different stages of myocardial infarction using the contrast agent gadolinium DTPA. Clin Cardiol 1986; 9: 527-35.

95. De Roos A, Doornbos J, Van der Wall EE, et al. MR imaging of acute myocardial infarction: Value of $\mathrm{Gd}$ DTPA. In: Braunwald E, ed. Year book of medicine. Chicago: Year Book Medical Publishers 1989; 323-5.

96. De Roos A, Doornbos J, Van der Wall EE, et al. MR imaging of acute myocardial infarction: Value of $\mathrm{Gd}$ DTPA. AJR 1988; 150: 531-4.

97. Wolf GL. Biological basis of proton relaxation. In: Marcus, Schelbert, Skorton, Wolf, eds. Cardiac Imaging. Saunders 1991; 40: 759-68. 